\title{
Emerging Infections in Renal Transplant Recipients. What has Changed in Recent Decades?
}

\section{Avelar Alves Da Silva*}

Department of General Practice, Division of Nephrology, Federal University of Piaui, USA

*Corresponding author: Avelar Alves Da Silva, Department of General Practice, Division of Nephrology, Federal University of Piaui, USA, Tel: +558699819904; E-mail: avelaralvesdasilva@gmail.com

Received date: April 27, 2015; Accepted date: March 25, 2017; Published date: April 01, 2017

Copyright: ( 2017 Alves Da Silva A. This is an open-access article distributed under the terms of the Creative Commons Attribution License; which permits unrestricted use; distribution; and reproduction in any medium; provided the original author and source are credited.

\section{Letter-to-Editor}

In the last four decades renal transplantation longer considered an experimental procedure and has evolved into the condition of an established therapeutic procedure as best therapy for end-stage renal disease (ESRD), as demonstrated over the years with remarkable improvement in quality of life, patient survival and renal grafts. We attribute this astronomical evolution to the emergence of new therapeutic agents, like immunosuppressive, antibiotics and antiviral $[1,2]$. Treatment with immunosuppressive rationally and increasingly selective in renal transplantation, greatly reduced the number of acute rejections, these until the 90s was the biggest ghost of transplantation teams. However immunosuppression creates an inseparable connection between infection and rejection, a fact that is very important for the transplantation teams, demonstrating that immunosuppression protocols should be flexible and not just focused on the graft, but the immunological, socioeconomic, geographic conditions and in the presence of comorbidities of renal allograft recipients. It is indisputable that the rate of infection is associated with the total increase of doses, the number of drugs used and the use of monoclonal antibodies in repeated episodes of rejection [3].

Concerning the prevalence and types of the most common infections in the first six months of postoperative are classic and already well-studied [4]. The major focus of the transplant is currently facing emerging and endemic infections coming affecting the patients receiving renal transplantation. Infections still unknown, there are few studies in the literature which complicates the diagnosis and therefore treatment, endangering patients and renal grafts [4].

In this large group of emerging agents, quoted infections caused by polyomavirus BK, which has been identified with high frequency and due to its histological characteristics to affect the renal graft mimics episode of acute rejection and is one of the factors responsible for chronic rejection renal graft. Still among viral infections, let us not forget the human parvovirus B19 causing aplastic anaemia and microangiopatics phenomena in renal graft [5].

Mycobacterial infections in transplant recipients that is 100 times more frequent than in the general population. The most common agent is Mycobacterium tuberculosis [6]. Another worrying agent in this specific population of patients is the infection by Nocardia asteroids, rare in many countries, but quite common in Brazil and could lead to a frightening number of more than $70 \%$ of deaths for patients with this infection. Among the parasitic infections, we can only report the infections caused by toxoplasma goondii that under conditions of immunosuppression affects the brain and eye region in renal transplant recipients, causing a mortality of more than $50 \%$ of patients $[7,8]$.
With the globalization of kidney transplantation has emerged a new group of infections, called endemic infections, more common in tropical and dry climate regions. Visceral leishmaniasis caused by Leishmania sp, in recent studies, if not diagnosed and not treated increased by more than 5 times the acute rejection episodes and by more than 4 times the prevalence of cytomegalovirus infection. This infection is more prevalent in patients living with cats and cultivating houseplants, recently published data and that directly interfere in the selection of patients eligible for kidney transplant recipients [9].

Other infections that fall in this group of tropical diseases are infections caused by Plasmodium sp, and infections by multiple serotypes of virus dengue. There is no specific treatment protocol for this virus in renal transplant recipients [10]. We are currently working and conducting research in this area, analysing the epidemiological, clinical and therapeutic aspects in patients affected by dengue virus.

In conclusion, infections in renal transplant recipients, regardless of their nature, source or location, are phenomena present during the life of the renal transplant recipient. What is believed is that these infections obey a well-established chronology that favoured the prophylaxis and treatment. However the latest research in this area show that it is no longer so true, resulting in new difficulties and learning for the transplantation teams, the need for new prophylactic schemes, the making of new immunosuppressive protocols and forcing us to meet these new infectious agents since the migration processes are increasingly frequent in this new scenario in which we are living.

\section{References}

1. Schweitzer EJ, Matas AJ, Gillingham KJ, Payne WD, Gores PF, et al. (1991) Causes of renal allograft loss. Progress in the 1980s, challenges for the 1990s. Ann Surg 214: 679-688.

2. Hill MN, Grossman RA, Feldman HI, Hurwitz S, Dafoe DC (1991) Changes in causes of death after renal transplantation, 1966 to 1987. Am J Kidney Dis 17: 512-518.

3. Diaz J, Henzo J, Rodelo J, Garcia A, Arbalaez M, et al. (2014) Incidence and risk factors for cytomegalovirus disease in a colombian cohort of kidney transplant recipients. Transplant Proc 46: 160-166.

4. Lapchik MS, Castelo Filho A, Pestana JO, Silva Filho AP, Wey SB (1992) Risk factors for nosocomial urinary tract and postoperative wound infections in renal transplant patients: A matched-pair case-control study. J Urol 147: 994-998.

5. Flaegstad T, Nilsen I, Skar AG, Taavik T (1991) Antibods against BK vírus in renal transplant patients sera: Results with five diferente methods indicative frequent reactivations. Scand J Infect Dis 23: 287-291.

6. Kristjansson M, Bieluch WM, Byeff PD (1991) Mycobacterium haemophilum infection in immunocompromised patients: Case report and review of the literature. Rev Infect Dis 13: 906-910. 
Citation: Alves Da Silva A (2017) Emerging Infections in Renal Transplant Recipients. What has Changed in Recent Decades?. J Nephrol Ther 7: 290. doi:10.4172/2161-0959.1000290

Page 2 of 2

7. Cunha S, Ferreira E, Ramos I, Martins R, de Freitas L, et al. (1993) Cerebral toxoplasmosis in a kidney transplant patient. A clinical case and review of the literature. Acta Med Port 6: 157-163.

8. Silva AA, Pacheco-Silva A, Sesso R, Oliveira RA, Matos EM, et al. (2014) Visceral Leishmaniasis in renal transplant recipientes: Study of 30 cases. J Nephrol Ther 4: 1-7.
9. Wiwanitkit V (2012) Dengue virus infection in renal allograft recipients. Transpl Infect Dis 14: 330.

10. Türkmen A, Sever MS, Ecder T, Yildiz A, Aydin AE, et al. (1996) Post transplant malaria. Transplantation 62: 1521-1523. 